\title{
Effect of the Initial Support of the Tunnel on the Characteristics of Rockburst: Case Study and Mechanism Analysis
}

\author{
Chunchi Ma $\mathbb{D},{ }^{1,2}$ Junqi Fan $\mathbb{D},,^{3}$ Xiang Ji $\mathbb{D},{ }^{1,2}$ Xiaoyan Shi, ${ }^{3}$ and Jun Zeng $\mathbb{C}^{1,2}$ \\ ${ }^{1}$ State Key Laboratory of Geohazard Prevention and Geoenvironment Protection, Chengdu University of Technology, \\ Chengdu 610059, Sichuan, China \\ ${ }^{2}$ School of Environment and Civil Engineering, Chengdu University of Technology, Chengdu 610059, Sichuan, China \\ ${ }^{3}$ Research Instiute for National Defense Engineering of Academy of Military Science PLA China, Luoyang 471023, Henan, China \\ Correspondence should be addressed to Chunchi Ma; machunchi17@cdut.edu.cn and Junqi Fan; lyfjq@163.com
}

Received 13 December 2021; Accepted 11 January 2022; Published 9 February 2022

Academic Editor: Ma Jianjun

Copyright (c) 2022 Chunchi Ma et al. This is an open access article distributed under the Creative Commons Attribution License, which permits unrestricted use, distribution, and reproduction in any medium, provided the original work is properly cited.

\begin{abstract}
Rockburst is still a stubborn disease in the field of engineering geology. The present research pays more attention to the influence of geological conditions on rockburst and less to the influence of type and stiffness of engineering support on rockburst. We explore the influence of support stiffness from weak to strong on rockburst and reveal the characteristics of fracture and microseismicity during rockburst through microseismic monitoring and numerical simulation. The main results and conclusions can be drawn: (1) Strong stiffness support makes the surrounding rock accumulates higher energy before rockburst. The evolution of microseismicity and its indexes can be used as precursors of potentially strong rockburst. (2) Strong stiffness support is easy to concentrate high stress under the action of surrounding rock pressure, and it is easy to fail under the disturbance of external load. This will produce a "sudden unloading effect" on the surrounding rock mass and may lead to a more serious rockburst. Numerical simulation verifies the existence of that effect and are consistent with the actual signs of failure. Our research is helpful to clarify the rockburst problem in the field of engineering geology, specifically to reveal the mechanism of rockburst and the early warning criteria of rockburst hazard under the action of supporting structure, which can provide practical data and theoretical support for scientific and reasonable prevention and control of rockburst risk in tunnel and underground engineering.
\end{abstract}

\section{Introduction}

Rockburst is a kind of geological hazard with complicated development mechanism, which is influenced by stratigraphic lithology, geological structure, ground stress and multi-field coupling factors and greatly threatens the field of geological engineering and geotechnical engineering. When the tunneling or underground opening is implemented in the hard-brittle rock under high ground stress, the stress adjustment will cause damage to the surrounding rock, so that the elastic strain energy stored in the rock mass will be released suddenly, resulting in loosening, spalling, ejection and even throwing. Rockburst is that a type of dynamic instability and geological disaster characterized by the abruptness and violent nature. Prediction and early warning of rockburst are challenging, posing significant challenges to the construction safety and, thus, necessitating continuous exploration of the development laws, early warning techniques, and support methods of deep geological disasters to serve the safety construction in deep engineering [1-5].

Due to the lack of deep understanding of rockburst, engineers may design the high-strength and high-stiffness support in tunnel to control the risk of rockburst, which contradicts the generally accepted principle of releasing rockburst energy. This may lead to the failure of the surrounding rock mass to give full play to the self-stability in the stress adjustment, thus increasing the accumulation of strain energy of surrounding rock and the destructiveness of rockburst. For example, when the initial support system was strengthened by shortening the spacing of the steel arch, the rockburst in the Bamiao tunnel of Taoba expressway intensified, and the initial lining near the tunnel face appeared 
large area exfoliation. Reinforced (rigid) support system has been carried out in the rockburst section of Micangshan tunnel of Bashan expressway, which poses a significant impact on the characteristics of rockburst and microseismicity.

To date, most of the researches on the influencing factors of rockburst, such as geo-stress, stratigraphic lithology, rock mass structure, topography, hydrology, excavation, and so on, have achieved outstanding results [6-11]; however, very limited studies have explored the impact of supporting structures on rockburst. For instance, Fan et al. [12] explored the influence of tunneling methods on the strainburst characteristics during the excavation. $\mathrm{Hu}$ [13] analyzed the response of support thickness to rockburst through numerical simulation, suggesting that support exerts an inhibitory effect on rockburst, but excessive support thickness might promote rockburst. Li et al. [14] determined the mechanical effects of rockburst by numerically changing the supporting parameters. Chen [15] investigated the rockburst under different densities of anchor arrangement, and thought that the rockburst under high density anchoring would lead to the overall damage of surrounding rock. In addition, Ortlepp [16,17] described the characteristics and extent of rockburst failure under different support strength, and he thought it is futile to improve the support strength to resist rockburst when strong rockburst may occur. Huang [18] investigated the rockburst development under different support strengths through numerical simulation and field tests. The above researches reveal to some extent the effect of supporting system on rockburst, but these conclusions are mostly qualitative or semi-quantitative.

The development of rockburst accompanies a series of microfracture (microseismic event). The microseisms determine the failure characteristics and mechanism of rockburst [19-24]. To date, the interactive mechanism between microseismic activity and supporting structure remains less investigated, and the microseismic activity is rarely used to guide support strategy. In some representative studies, support system was determined based on the microseismic data in the underground cavern of a hydropower station [25]. Hu et al. [26] used the microseismic monitoring to investigate the deformation and failure of surrounding rock in an underground laboratory, and proposed reasonable schemes of excavation and support. Gale [27] enhanced the support structure by comparing microseismic data and numerical simulation of different mining areas. In fact, the initial support structure of the tunnel (such as support type, support strength, support stiffness, and support timing) exerts marked impact on the microseismic activity and rockburst. It is imperative to study the influence mechanism of the support system on fractures or microseismic activities of the surrounding rock mass.

To investigate the impact of the initial support system on rockburst, this study aims to explore the rockburst characteristics and microseismic activity under weak and strong stiffness of support based on the phenomena and data collected in the Micangshan tunnel of the Sichuan-Shaanxi expressway, combined with numerical simulation to elucidate the mechanism of the supporting structure affecting rockburst characteristics and intensity. This study will provide practical data and theoretical guidance for the reasonable strategy of supporting the rockburst and the consideration of the rockburst warning criterion affected by the support stiffness. The relevant results are helpful to reveal the rockburst mechanism under deep engineering activities and to effectively prevent and control underground engineering disasters.

\section{Rockburst Influenced by Tunnel Initial Support}

2.1. Composite Stiffness Assessment of Tunnel Support and Surrounding Rock. In order to distinguish the rockburst characteristics corresponding to different support stiffness, it is necessary to establish a method to determine the support stiffness. However, because the initial support of the tunnel is a composite system composed of a variety of supporting structures (such as shotcrete and steel arch frame), it is very challenging to propose a quantitative method for evaluating the composite stiffness. For this reason, This work is based on the empirical judgment of the effectiveness of various support types and support parameters in the actual construction of Micangshan tunnel (which may change due to engineering characteristics and geological types), a semi quantitative evaluation method of composite system stiffness considering both surrounding rock stiffness and initial support mode is proposed. As shown in Table 1, the stiffness evaluation method consists of two parts: the basic value $\mathrm{A}$ and the construction parameter $\mathrm{B}$. Of these, The basic value $A$ is the empirical value considering the support type and support specification for stiffness. the construction parameter $\mathrm{B}$ considers the contribution of the engineering dosage of each support type to the stiffness. The stiffness evaluation of surrounding rock has no basic value, which depends on the contribution of lithology quality grade to stiffness [28].

Specification of structure: steel arch- type I18, height $180 \mathrm{~mm}$, width $94 \mathrm{~mm}$ and thickness $10.7 \mathrm{~mm}$; anchor- diameter $22 \mathrm{~mm}$ and length $3 \mathrm{~m}$; shotcrete- type C20. The determination of $\mathrm{A} / \mathrm{B}$ value should also refer to the specific geological conditions of each project.

\subsection{Rockburst Characteristics Affected by the Tunnel Initial} Support. The Micangshan extra-long tunnel of SichuanShaanxi expressway is about $13.8 \mathrm{~km}$ in length, which was designed as the second longest expressway tunnel in China and the third longest in the world. In the excavation of K46+170-K45+800 mileage section of the tunnel, rockburst hazards caused by the high ground stress occurred frequently. As shown in Figure 1, "12.17" rockburst, "12.29" rockburst, "01.14" rockburst, "03.12" rockburst and so on. The rockburst areas have the following conditions: the buried depth is 530-760 $\mathrm{m}$ and the lithology is mainly gabbro and tectonic granulite; the grade of surrounding rock mass is mainly grade III (medium), and grade II (better) or grade IV (poor) in local; the gabbro and tectonic granulite are interlaced and rockburst generally occurs in the location of tectonic granulite. According to the identification, the 
TABLE 1: Stiffness score of support and surrounding rock in Micangshan tunnel [28].

\begin{tabular}{lccc}
\hline Type & Basic value/ A & Construction parameter/ B & Score \\
\hline Steel arch & 10 & Spacing $(\mathrm{m})$ & $\mathrm{A} \times(1 / \mathrm{B})$ \\
Strengthened steel arch & 15 & Spacing $(\mathrm{m})$ & $\mathrm{A} \times(1 / \mathrm{B})$ \\
Anchor & 1 & Anchor number per steel arch & $\mathrm{A} \times \mathrm{B}$ \\
Shotcrete & 2 & Thickness $(\mathrm{cm})$ & $\mathrm{A} \times(\mathrm{B} / 10)$ \\
Pre-grouting & 3 & Volumes $\left(\mathrm{m}^{3}\right)$ & $\mathrm{A} \times \mathrm{B}$ \\
Pressure release blasting & 2 & Number of boreholes & $-\mathrm{A} \times \mathrm{B}$ \\
Surrounding rock mass & - & Grades (I-V) & $\mathrm{I}-50 ;$ II- $40 ;$ III- $30 ;$ IV- $20 ; \mathrm{V}-10$ \\
\hline
\end{tabular}

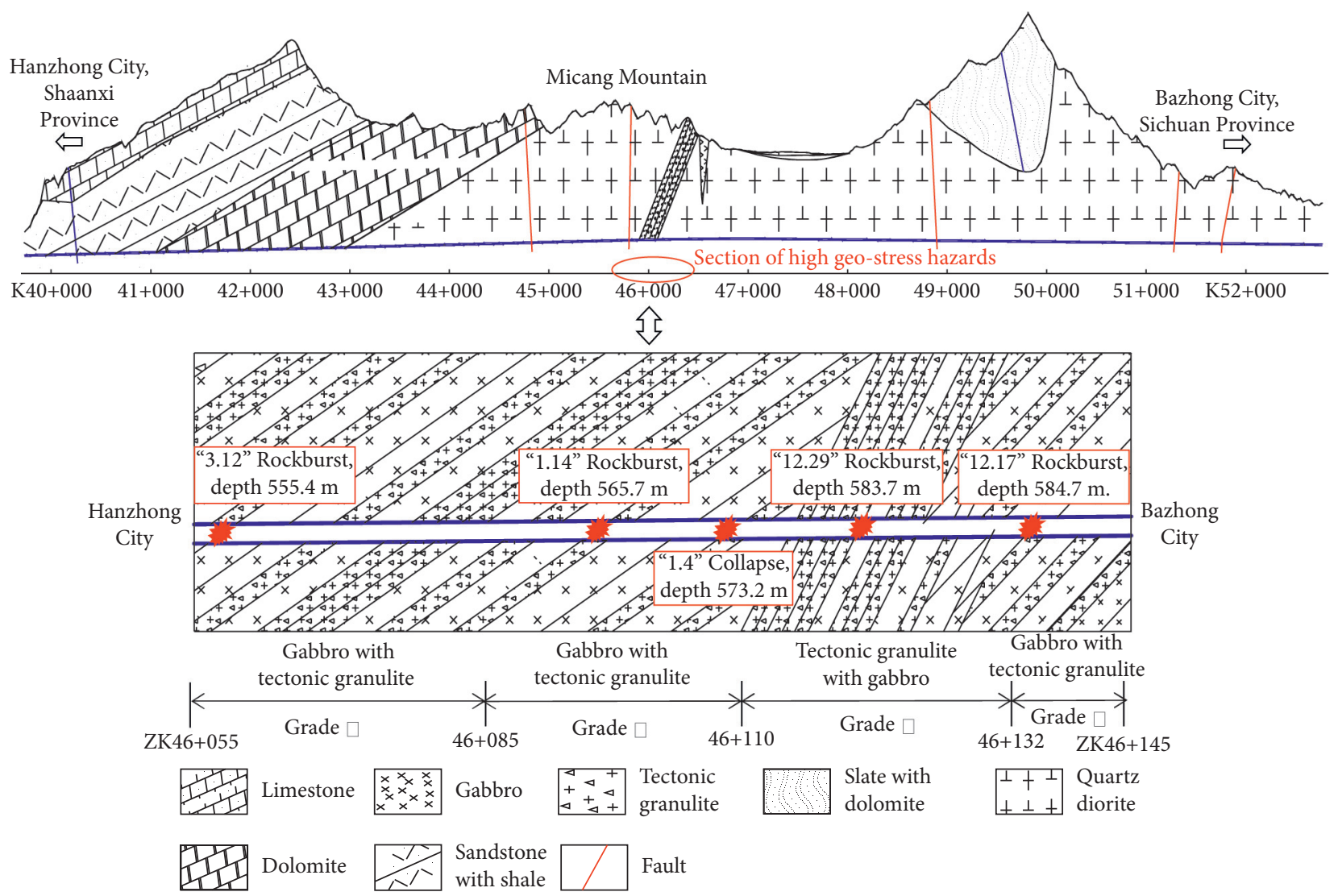

Figure 1: The geological cross-section along the Micangshan tunnel, China [28].

original rock of tectonic granulite should be gabbro, which undergo compressive rupture and recrystallize to form granulite. There are many microfractures in the rock mass, but it still has high residual ground stress, which satisfies the occurrence conditions of rockburst. Due to the occurrence of different degrees of rockburst, various support measures have been adopted in the construction site. In order to distinguish the stiffness changes of various support measures and study the influence of initial support stiffness on the characteristics of rockburst, the comprehensive stiffness evaluation method in Table 1 is used to evaluate the stiffness changes of " 12.17 " rockburst, " 12.29 " rockburst, " 01.14 " rockburst and "03.12" rockburst. As shown in Table 2, in comparison, the score of surrounding rock-support composite stiffness of " 1.14 " rockburst and " 3.12 " rockburst is higher than that of 12.17 "rockburst and" 12.29 "rockburst. Therefore, the " 12.17 " rockburst and the " 12.29 " rockburst is simply expressed as weak stiffness rockbursts, and the "1.14" rockburst and " 3.12 " rockburst is simply expressed as strong stiffness rockburst.

Tunnel support can be divided into initial support and secondary support. The initial support is carried out immediately after the excavation of the tunnel, and is the main structure to bear the pressure of surrounding rock. Experts suggest adopting flexible support system for the initial support of rockburst and following the principle of absorbing high energy, that is, the supporting structure should not only satisfy a certain strength but also can deform greatly, thus absorbing the kinetic energy of rockburst $[17,29]$. However, high strength and high stiffness support are often used in rockburst due to the lack of comprehensive understanding of rock mass fractures. Such treatment lacks theoretical basis and is often controversial. For example, the Micangshan tunnel shows the rockburst intensity varying 
TABLE 2: Composite stiffness of surrounding rock and support system in rockburst.

\begin{tabular}{|c|c|c|c|c|}
\hline Hazards & Rockburst “12.17” & Rockburst "12.29" & Rockburst "01.14" & Rockburst “03.12” \\
\hline Time span & $2017 / 12 / 15-12 / 17$ & $2017 / 12 / 26-12 / 29$ & 2018/01/10-01/14 & 2018/03/08-03/12 \\
\hline Lithology & $\begin{array}{l}\text { Gabbro with granulite } \\
\text { interbedded, grade III }\end{array}$ & $\begin{array}{l}\text { Granulite with gabbro } \\
\text { interbedded, grade IV }\end{array}$ & $\begin{array}{l}\text { Gabbro with granulite } \\
\text { interbedded, grade III }\end{array}$ & $\begin{array}{l}\text { Gabbro with granulite } \\
\text { interbedded, grade III }\end{array}$ \\
\hline $\begin{array}{l}\text { Support } \\
\text { structure and } \\
\text { parameter }\end{array}$ & $\begin{array}{l}\text { Steel arch: spacing } 80 \mathrm{~cm} \text {. } \\
\text { Anchor: } 12 \text { per steel arch. } \\
\text { Shotcrete: thickness } 20 \mathrm{~cm} \text {. }\end{array}$ & $\begin{array}{l}\text { Steel arch: spacing } 80 \mathrm{~cm} . \\
\text { Anchor: } 12 \text { per steel arch. } \\
\text { Shotcrete: thickness } 20 \mathrm{~cm} .\end{array}$ & $\begin{array}{l}\text { Strengthened steel arch: } \\
\text { spacing } 70 \mathrm{~cm} \text {. Anchor: } 20 \text { per } \\
\text { steel arch. Shotcrete: thickness } \\
20 \mathrm{~cm} \text {. }\end{array}$ & $\begin{array}{l}\text { Steel arch: spacing } 60 \mathrm{~cm} . \\
\text { Anchor: } 12 \text { per steel arch. } \\
\text { Shotcrete: thickness } 20 \mathrm{~cm} \text {. }\end{array}$ \\
\hline $\begin{array}{l}\text { Stiffness score } \\
\text { Stiffness (For } \\
\text { these four } \\
\text { rockbursts) }\end{array}$ & Weak stiffness & Weak stiffness & Strong stiffness & Strong stiffness \\
\hline
\end{tabular}

with the change of initial support stiffness. In order to further explore this change law, a microseismic monitoring system was established in Micangshan Tunnel to capture microseismic events and rockburst evolution. As shown in Figure 2, The microseismic sensor array is deployed as three rows: two rows in the leading tunnel, one row in the following tunnel, and three sensors in each row, which ensures the precision of microseismic source location and the effectiveness of the source parameters.

Figure 3 records the rockburst evolution in the following tunnel of the twin-tube Micangshan tunnel. The three cases of rockburst disasters had developed in the period 2017/12/ 16-2018/01/14 (pentagram denotes the rockburst time). The first "12.17 rockburst" occurred in grade-III surrounding rock. The initial support was composed of steel arch and shotcrete anchor (weak stiffness). The rockburst occurs with a thunder-like bang and subsequent splitting sound, and the broken rocks are ejected or collapsed. Most of rockburst zones are controlled by a single set of dominant structural planes, or presents a wedge or fornix shape controlled by two or more sets of structural planes, with a maximum depth of up to $3 \mathrm{~m}$. The second " 12.29 rockburst" occurred in gradeIII or IV surrounding rock. The advanced grouting was used in the local broken surrounding rock, and the stiffness of the support system was slightly higher than that of the previous rockburst (weak stiffness). The maximum energy of microseismic event can reach one million joules, which is even comparable to the tunnel blasting. Strong energy releases impact on the equipment and surrounding rock mass of the tunnel, resulting in large mechanical shaking or overturning, cracking of the tunnel floor (floor heave), cracking of the sidewall (sidewall heave), and initial support failure. The third "01.14 rock burst" occurred in grade-II or III surrounding rock. Because of the frequent rockburst, the number of bolts in each construction period increased, the double-layer steel arch was adopted in local, and the support stiffness was the highest at this time. During the rockburst, the frequency of thunderous roar and splitting sound increased significantly, and the development period of the third rockburst was prolonged, the energy release was increased, and the crack range of lining caused by rockburst was enlarged.

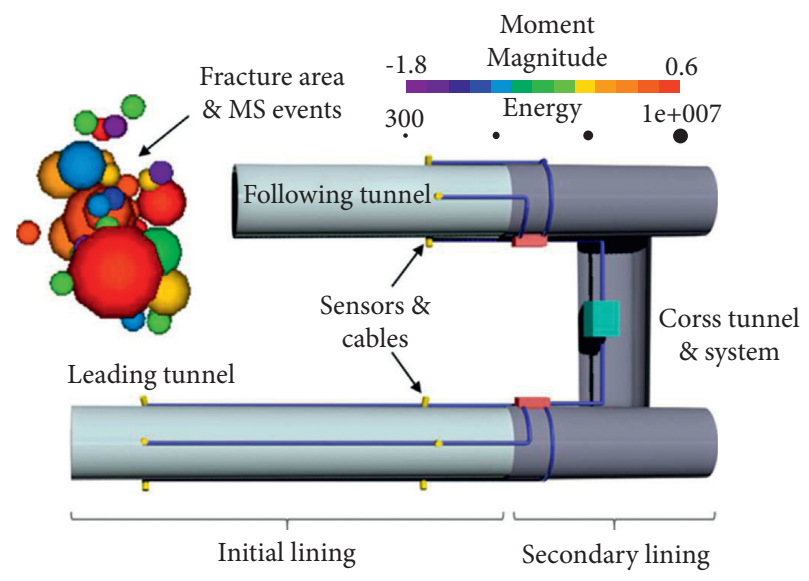

FIgURE 2: The layout of the microseismic monitoring system in the Micangshan tunnel.

\subsection{Interpreting the Effect of Support Stiffness on Rockburst by} Microseismic Characteristics. The microseismic indexes are introduced to elucidate the characteristics and mechanism of rockburst, and the process is divided as the developmental stage and occurrence stage. The occurrence time of rockburst is easily recorded by the microseismic monitoring system, and the period before rockburst is considered to be the developmental stage. For example, "12.29 rockburst" is a weak-stiffness rockburst and " 1.14 rockburst" is a strongstiffness rockburst. These rockbursts are developed in similar environment of lithology, buried depth and ground stress, and the space distance is close (Figure 1); therefore, we think that the main factor causing the change of rockburst intensity and characteristics is the support stiffness. Figure 4 shows the characteristics of the number of microseismic events and the incidence of high energy in rockburst process under strong and weak support stiffness. The seismic energy $E$ denotes the elastic strain energy released by rock mass fracture:

$$
E=\left(\frac{8}{5}\right) \pi \rho v R^{2} \int_{0}^{t_{s}} \bar{u}_{\text {corr }}^{2}(t) \mathrm{d} t .
$$

$\rho$ denotes the rock mass density; $v$ denotes the microseismic velocity; $R$ denotes the hypocentral distance; $t_{\mathrm{s}}$ denotes 


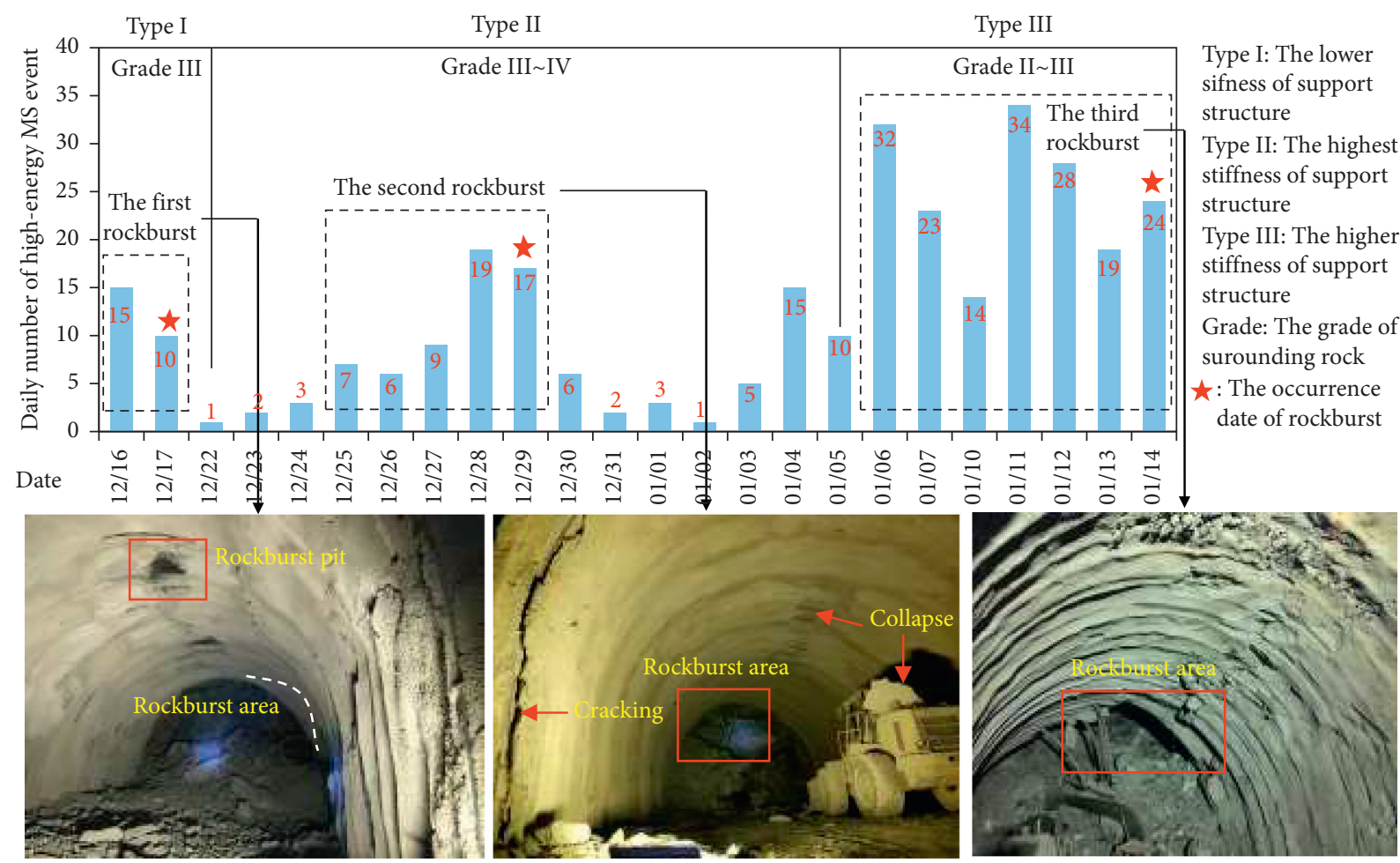

FIGURE 3: The record of the rockburst evolution during construction in the Micangshan tunnel (2017-2018).

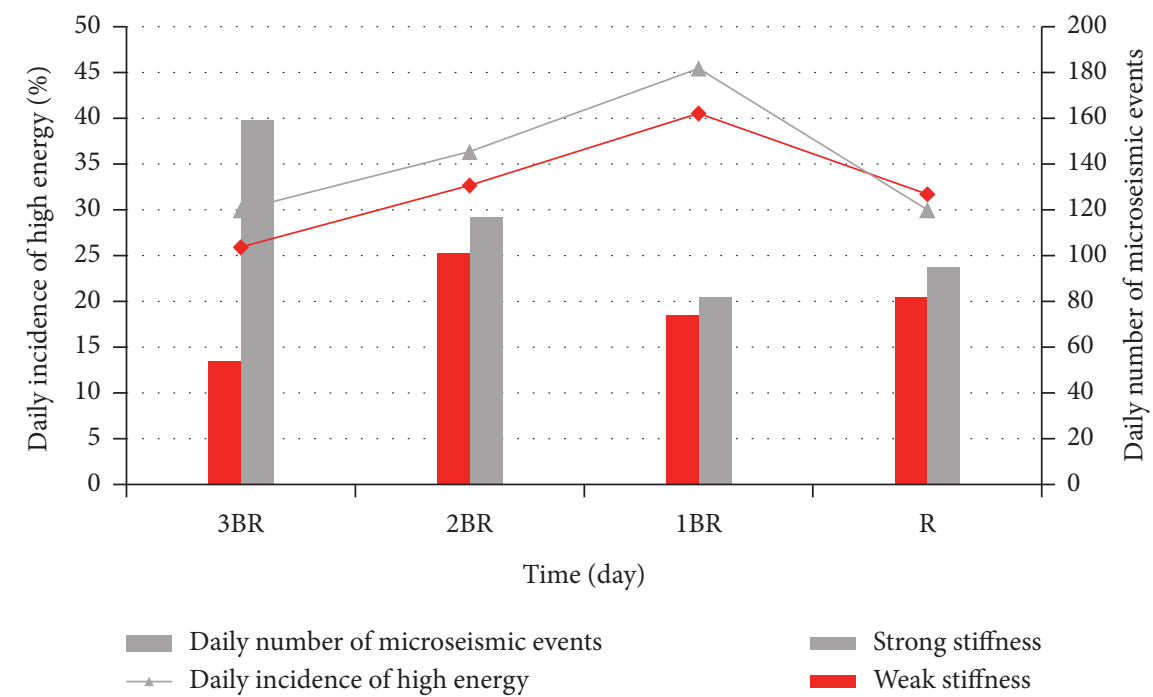

FIGURE 4: Characteristics of daily microseismic events and high energy incidence in rockburst process.

the time span of microseismic signal; $u_{\text {corr }}$ denotes the displacement function of microseismic wave at the receiving end [25]. The number of daily cumulative microseismic events of rockburst under the condition of strong stiffness is obviously more than that of weak stiffness. The daily occurrence rate of high energy of rockburst is higher than that of weak stiffness under the condition of strong stiffness in the first 3 days before the occurrence of rockburst. But under the condition of strong stiffness on the day of rockburst, the daily incidence of high energy of rockburst is lower than that of weak stiffness.

Figure 5 shows the moment magnitude variation characteristics of microseismic events in rockburst process under strong support stiffness and weak support stiffness. Moment magnitude $\mathrm{M}_{\mathrm{w}}$ is determined by seismic moment 


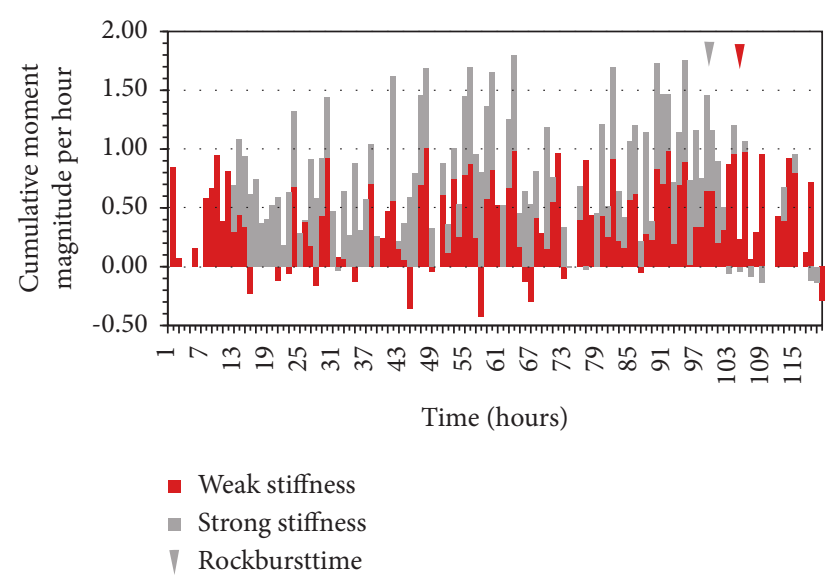

FIGURE 5: Characteristics of moment magnitude of microseismic events in rockburst process.

calculation, which can directly represent the intensity of a microseismic event [30]:

$$
M_{w}=\frac{2}{3} \log _{10} M_{0}-6.0 \text {. }
$$

$\mathrm{M}_{0}$ is the seismic moment, that is, the point source moment equivalent to the source fault dislocation that caused the earthquake $(N \cdot m)$. In order to explore the characteristics of the moment magnitude of the microseismic event per hour before the rockburst, this study defines the sum of the moment magnitude of the microseismic event per hour as the hourly cumulative moment magnitude:

$$
M_{h}=\sum_{i=1}^{n} M_{w},
$$

where $\mathrm{M}_{\mathrm{h}}$ is the cumulative moment magnitude per hour, $\mathrm{n}$ is the number of microseismic events within one hour, and $\mathrm{M}_{\mathrm{w}}$ is the magnitude of a single microseismic event. It can be found that the hourly cumulative moment magnitude of microseismic events under the condition of strong stiffness before rockburst (development period) is higher than that of weak stiffness condition. under the condition of weak stiffness after the occurrence of rockburst, the cumulative moment magnitude of microseismic events per hour of rockburst is obviously higher than that of strong stiffness. It is worth noting that the cumulative moment magnitude per hour after the occurrence of rockburst decreased obviously under both conditions.

Figure 6 reveals the characteristics of average displacement of microseismic source in rockburst process under strong support stiffness and weak support stiffness. The deformation caused by the rupture of source rock mass can be expressed by displacement, which can be expressed as follows:

$$
\bar{D}=\frac{M_{0}}{\mu \pi r_{0}^{2}} .
$$
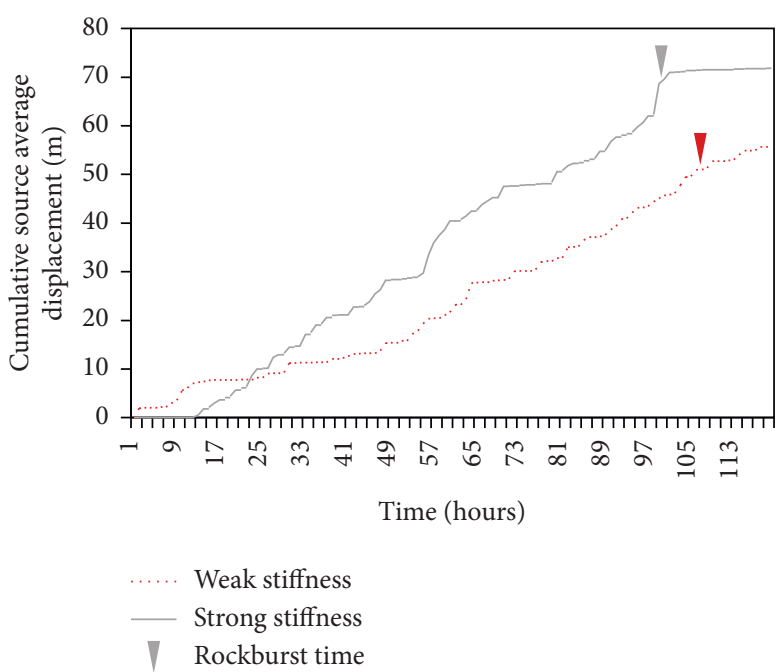

FIgURE 6: Characteristics of source average displacement in rockburst process.

$\mu$ is the shear modulus of rock mass, $\mathrm{M}_{0}$ is the seismic moment, and $\mathrm{r}_{0}$ is the radius of the fault plane [25]. It can be obviously found that the cumulative source average displacement of strong rigid rockburst is much higher than that of weak stiffness rockburst, and the trend characteristic of strong stiffness rockburst is more significant; after the occurrence of rockburst, strong stiffness rockburst basically does not change, weak stiffness rockburst continues to increase slowly.

Figure 7 shows the apparent volume series of rockburst developmental and occurrence stages under both strong and weak support stiffness. The apparent volume index $V_{\mathrm{A}}$ reflects the volume of inelastic shear deformation of rock mass:

$$
V_{A}=\frac{M_{0}^{2}}{2 \mu E} .
$$

$\mu$ is the shear modulus of rock mass, $\mathrm{M}_{0}$ is the seismic moment, and $\mathrm{E}$ is the microseismic energy [31]. In the developmental stage, the mean apparent volume of strongstiffness rockburst $\left(370 \mathrm{~m}^{3}\right)$ is higher than that of weakstiffness rockburst $\left(330 \mathrm{~m}^{3}\right)$. In the occurrence stage, the apparent volume of strong-stiffness rockburst increases obviously, but then decays rapidly, and the average value $\left(397 \mathrm{~m}^{3}\right)$ is lower than that of the weak-stiffness rockburst $\left(438 \mathrm{~m}^{3}\right)$.

Figure 8 describes the source parameter space of microseismic event during the developmental stage of rockburst; the abscissa of the microseismic parameter space is the apparent volume, the ordinate is the seismic energy, and the microseismic event (small dot) can be located in this space. When the stiffness of the support system changes from weak to strong, the microseismic events migrate toward the direction of arrow in the figure, indicating that the proportion of the small energy and the large apparent volume event increases. Based on the statistics in the development stage (Table 3), the proportion of small-energy events increases 


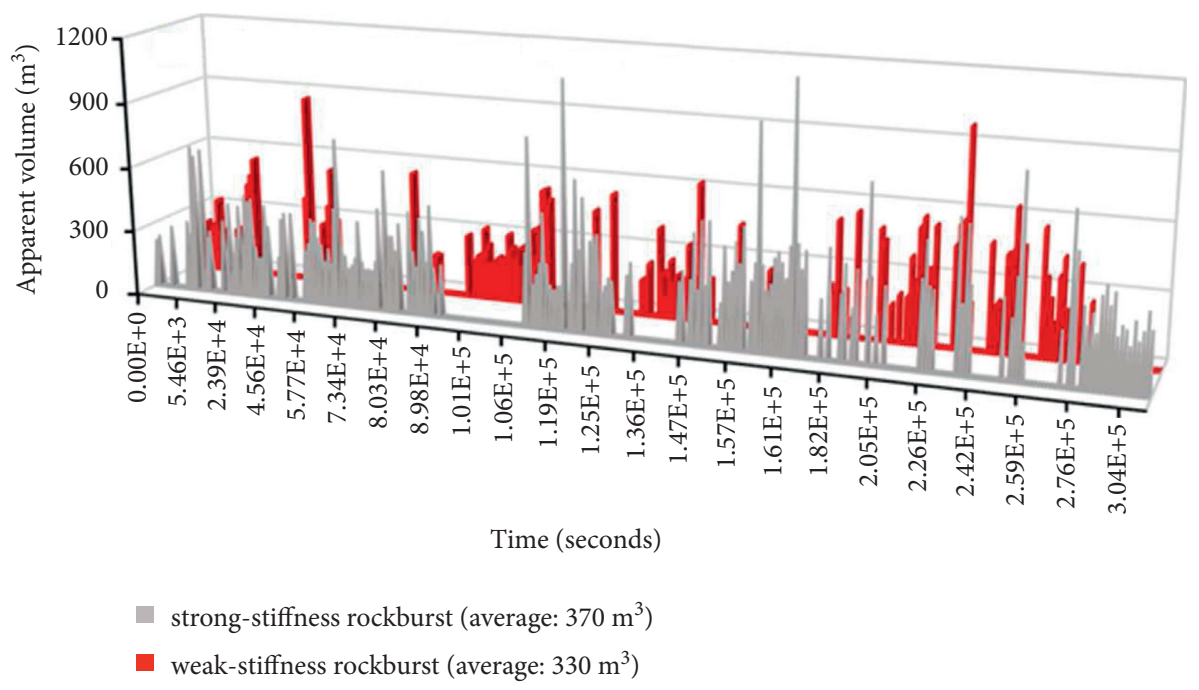

(a)

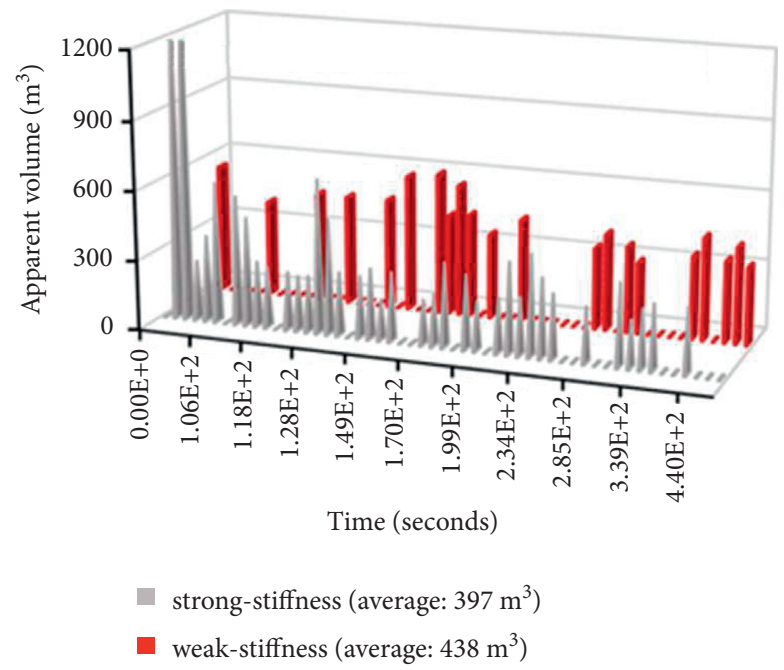

(b)

Figure 7: The apparent volume series of microseismic events during rockburst: (a) the development stage; and (b) the occurrence stage.

when the support stiffness changes from weak to strong, and the proportion of medium- and large-energy events decreases. Meantime, the proportion of small-volume events decreases, but the proportion of medium-volume events increases.

Classification of energy: small-energy event $\left(\leq 10^{4} \mathrm{~J}\right)$, medium-energy event $\left(10^{4}-10^{5} \mathrm{~J}\right)$, and large-energy event $\left(\geq 10^{5} \mathrm{~J}\right)$ [32]. Classification of apparent volume: small-volume event ( $\leq$ $\left.200 \mathrm{~m}^{3}\right)$, medium-volume event $\left(200-400 \mathrm{~m}^{3}\right)$, and largevolume event $\left(\geq 400 \mathrm{~m}^{3}\right)$ [28].

According to the indexes summarized in Table 4, the support stiffness poses great influences on rockburst, and they can be described as follows:

(1) The reinforcement of the support stiffness imposes a more rigid constraint on the surrounding rock, which means a stronger confining pressure (support pressure) on the surrounding rock. In the process of rockburst, the high energy incidence of stress adjustment activities increased, the development time of rockburst prolonged and the number of microseismic events increased.

(2) with the increase of rigid constraint, the surrounding rock mass is easier to accumulate energy. The greater the moment magnitude of the microseismic event is in the process of stress adjustment.

(3) The reinforcement of the support stiffness indicates that the stress adjustment of surrounding rock requires a larger apparent volume of source. This is similar to the fact that the process of deformation, damage and near-critical failure of surrounding rock needs to be accompanied by large deformation by the increase of confining pressure. The average apparent 


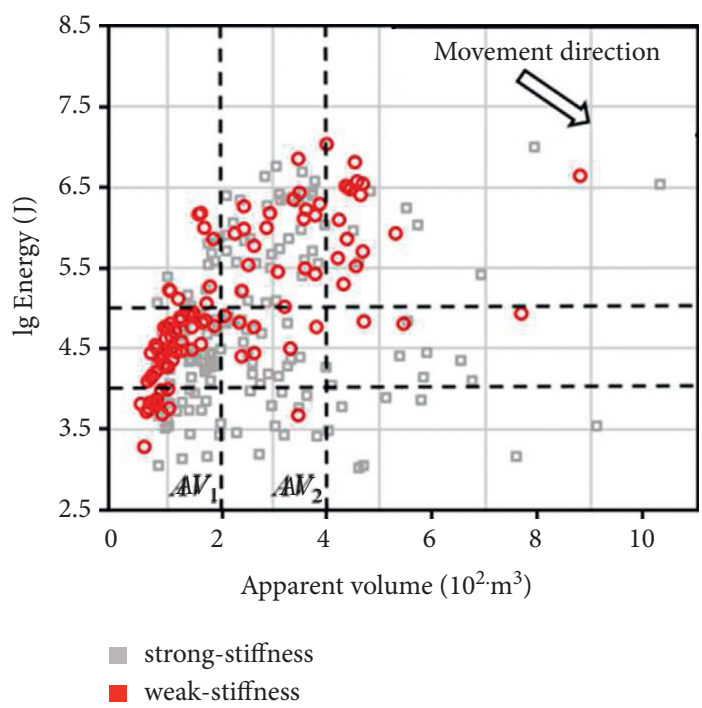

FIGURE 8: The source parameter space of the microseismic event during rockburst development stage. $(\mathrm{E})_{1}=4$ and $(\mathrm{E})_{2}=5$ are the threshold for small-energy events, medium-energy events, and large-energy events, respectively. $A V_{1}=200$ and $A V_{2}=400$ are the threshold for smallvolume events, medium-volume events, and large-volume events, respectively.

TABLe 3: Statistics of microseismic event types in development stage of rockburst.

\begin{tabular}{lcccccc}
\hline \multirow{2}{*}{ Rockburst } & \multicolumn{3}{c}{$\begin{array}{c}\text { Event type by seismic } \\
\text { energy }\end{array}$} & $\begin{array}{c}\text { Event type by apparent } \\
\text { volume }\end{array}$ \\
& Small & Medium & Large & Small & Medium & Large \\
\hline Low stiffness & $13.0 \%$ & $45.4 \%$ & $41.6 \%$ & $57.4 \%$ & $25.0 \%$ & $17.6 \%$ \\
High stiffness & $25.2 \%$ & $40.5 \%$ & $34.3 \%$ & $42.9 \%$ & $41.7 \%$ & $15.4 \%$ \\
\hline
\end{tabular}

volume during the rockburst development increases, and the average displacement of cumulative source also increases significantly.

(4) In the source parameter space composed of seismic energy and apparent volume, the motion path of microseismic events points to the lower right due to the enhancement of support stiffness, which indicates that the type of microseismic events changes and the proportion of events with both low energy and large apparent volume increases. The stress adjustment activities in the rockburst development tend to generate energy accumulation and energy transfer, and lead to stronger energy release in the occurrence stage of rockburst.

\section{Numeric Simulation and Interpretation of Rockburst Effect}

3.1. Modeling and Simulation Scheme. We established a tunneling model to simulate the rockburst affected by the drilling and blasting method in the Micangshan tunnel (Figure 9). Block-Dyna, a block-dynamic simulation software based on continuous-discontinuous method (CDEM), is used to simulate the whole process of damage and fracture of the tunnel surrounding rock under the action of static and dynamic loads. The software simulates the progressive failure process of materials by using the continuous medium characteristics of block characterization materials and the discontinuous medium characteristics of materials characterized by the interface between blocks. The software can simulate not only a variety of damage and failure processes of materials under static and dynamic loads, but also a series of mechanical processes of bulk after crushing. The overall size of the model is $50 \mathrm{~m}$ (hight) $\times 50 \mathrm{~m}$ (width) and the tunnel size is $8 \mathrm{~m} \times 12 \mathrm{~m}$, which includes the numbers of nodes and elements, 29302 and 54900, respectively. The tunnel length is $40 \mathrm{~m}$, which is designed as step by step excavation ( $5 \mathrm{~m}$ per step). The model is composed of excavation body, surrounding rock mass and lining of the tunnel; the thickness of the lining is set to $20 \mathrm{~cm}$ and implemented immediately after the excavation step; the monitoring points for the lining and surrounding rock mass are set up. The actual stress conditions are applied to the model: the maximum principal stress $\sigma_{1}$ near the vertical direction is $25.2 \mathrm{MPa}$; the intermediate principal stress $\sigma_{2}$ near the axial direction of the tunnel is $13.1 \mathrm{MPa}$; the minimum principal stress $\sigma_{3}$ near the horizontal direction is $12.9 \mathrm{MPa}$. Finally, we designed the two schemes of rockburst simulation according to the actual engineering situation.

(1) Simulation of weak-stiffness rockburst under static load. Weak parameters of deformation and strength are used for lining support, and strain softening model is used for surrounding rock mass and lining. Rockburst occurs after the five-step excavation of the tunnel.

(2) Simulation of strong-stiffness rockburst under static and dynamic loads. Because strong stiffness support is also of high strength, rockburst does not generally occur under a single static loading condition, but needs to occur under the additional energy disturbance provided by dynamic load. In this simulation, 
TABLE 4: Evolution of rockburst index with the strengthening of support stiffness.

\begin{tabular}{|c|c|c|c|}
\hline \multirow{2}{*}{ Index } & \multirow{2}{*}{$\begin{array}{l}\text { Rockburst } \\
\text { stage }\end{array}$} & \multicolumn{2}{|c|}{ Stiffness condition } \\
\hline & & Weak stiffness & Strong stiffness \\
\hline \multirow[t]{2}{*}{$\begin{array}{l}\text { Event type by seismic } \\
\text { energy }\end{array}$} & Development & $\begin{array}{l}\text { The type of medium and large energy event is } \\
\text { more, and the small energy event is less. }\end{array}$ & $\begin{array}{c}\text { The type of medium, large energy event } \\
\text { decreases, and the small-energy event } \\
\text { increases. }\end{array}$ \\
\hline & Occurrence & Mixed large and small energy events. & The large energy event is dominant. \\
\hline \multirow{2}{*}{ Daily high energy rate } & Development & The daily high energy rate increases gradually. & $\begin{array}{l}\text { The daily high energy rate increases gradually } \\
\text { and higher than weak stiffness. }\end{array}$ \\
\hline & Occurrence & Daily high energy rate decreases. & $\begin{array}{c}\text { Daily high energy rate decreases and lower } \\
\text { than weak stiffness. }\end{array}$ \\
\hline \multirow{2}{*}{$\begin{array}{l}\text { Cumulative moment } \\
\text { magnitude per hour }\end{array}$} & Development & Increase of high moment magnitude. & $\begin{array}{l}\text { Increase of high moment magnitude and the } \\
\text { whole is higher than the weak stiffness. }\end{array}$ \\
\hline & Occurrence & $\begin{array}{l}\text { The cumulative moment magnitude per hour } \\
\text { decreased obviously. }\end{array}$ & $\begin{array}{c}\text { The cumulative moment magnitude per hour } \\
\text { decreased obviously, but lower than weak } \\
\text { stiffness. }\end{array}$ \\
\hline \multirow{2}{*}{$\begin{array}{l}\text { Cumulative } \\
\text { microseismic source } \\
\text { average displacement }\end{array}$} & Development & Slow growth & Rapid growth and sudden increase. \\
\hline & Occurrence & Slow growth & No significant changes. \\
\hline \multirow{2}{*}{$\begin{array}{l}\text { Event type by apparent } \\
\text { volume }\end{array}$} & Development & $\begin{array}{l}\text { The type of small volume event is more, and } \\
\text { the other types are less. }\end{array}$ & $\begin{array}{c}\text { The type of small volume event decreases } \\
\text { largely, and the medium volume event } \\
\text { increases. }\end{array}$ \\
\hline & Occurrence & $\begin{array}{c}\text { Mixed extremely-larege, large and small } \\
\text { volume event. }\end{array}$ & The large volume event is dominant. \\
\hline \multicolumn{2}{|c|}{ Site characteristics of rockburst } & $\begin{array}{l}\text { Rockburst occurs on the excavation surface or } \\
\text { tunnel roof, and is controlled by a single or } \\
\text { multiple sets of structural plane, which could } \\
\text { cause initial support cracking and fall of } \\
\text { ground. }\end{array}$ & $\begin{array}{c}\text { Rockburst possesses the features of strong } \\
\text { energy release and large affected range, which } \\
\text { can trigger side wall heave, floor cracking or } \\
\text { floor heave in the same tunnel or adjacent } \\
\text { tunnel. }\end{array}$ \\
\hline
\end{tabular}
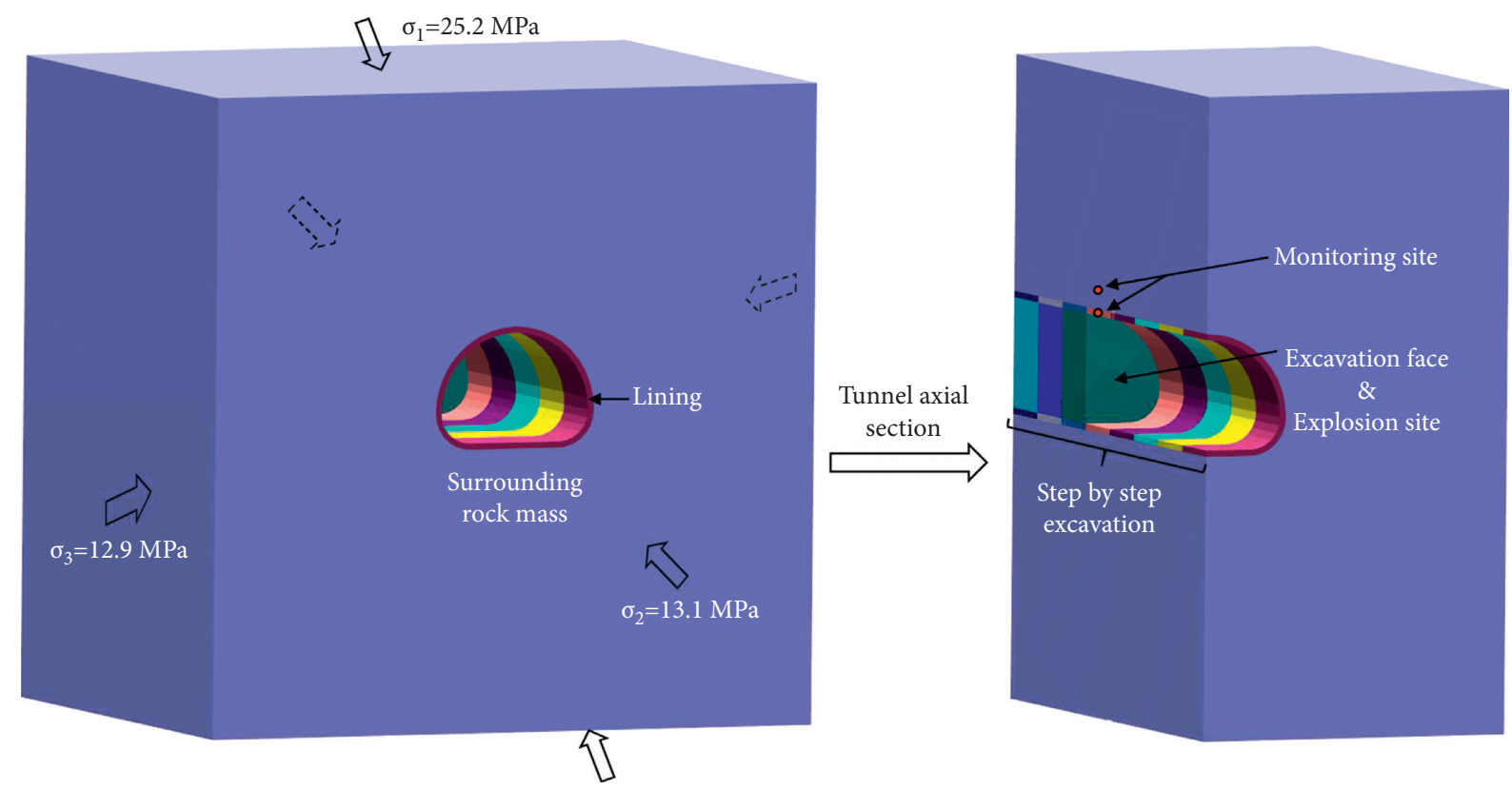

Figure 9: The excavation and blasting model of the Micangshan tunnel.

strong parameters of deformation and strength are used for lining support, and strain softening model is used for surrounding rock mass and lining.
Rockburst occurs after the five-step excavation of the tunnel and the excavation face is blasted. The calculation parameters are presented in Table 5 . 
The Mohr-Coulomb strain softening model is introduced to describe the damage and fracture behavior of the rock mass:

$$
\begin{aligned}
& C= \begin{cases}C_{0}\left(1-\frac{\left|\gamma_{p}\right|}{\gamma_{\lim }}\right), & \left(\left|\gamma_{p}\right|<\gamma_{\text {lim }}\right), \\
0, & \left(\left|\gamma_{p}\right| \geq \gamma_{\lim }\right),\end{cases} \\
& T= \begin{cases}T_{0}\left(1-\frac{\varepsilon_{p}}{\varepsilon_{\lim }}\right), & \left(0<\varepsilon_{p}<\varepsilon_{\lim }\right), \\
0, & \left(\varepsilon_{p} \geq \varepsilon_{\lim }\right),\end{cases}
\end{aligned}
$$

In the formula, $C, C_{0}, T$ and $T_{0}$ represent the current and initial values of cohesion and tensile strength, respectively; $\gamma_{\mathrm{p}}, \gamma_{\mathrm{lim}}, \varepsilon_{\mathrm{p}}$ and $\varepsilon_{\mathrm{lim}}$ represent the current and limit values of shear plastic strain and tensile plastic strain, respectively. According to the experiments and recommended values, $\gamma_{\text {lim }}=0.03$ and $\varepsilon_{\text {lim }}=0.01$. The strain softening model realizes the linear deterioration of the cohesion and the tensile strength with the plastic strain.

The Landau explosion source model is introduced to realize the tunnel blasting simulation:

$$
\begin{aligned}
& \left.\begin{array}{ll}
P V^{\gamma}=P_{0} V_{0}^{\gamma} & \left(P \geq P_{k}\right) \\
P V^{\gamma_{1}}=P_{k} V_{k}^{\gamma_{1}} & \left(P \geq P_{k}\right)
\end{array}\right\}, \\
& P_{0}=\frac{\rho_{w} D^{2}}{2(\gamma+1)} \\
& P_{k}=P_{0}\left\{\frac{\gamma_{1}-1}{\gamma-\gamma_{1}}\left[\frac{(\gamma-1) Q_{w} \rho_{w}}{P_{0}}-1\right]\right\}^{(\gamma / \gamma-1)} .
\end{aligned}
$$

The blasting source model is based on the Landau-Stan Newkovic formula. $\gamma=3, \gamma_{1}=4 / 3 ; P, P_{0}, V$ and $V_{0}$ represent the current and initial values of explosive gas pressure and volume, respectively; $P_{\mathrm{k}}$ and $V_{\mathrm{k}}$ represent the pressure and volume of explosive gas on the boundary of two-stage insulation process; $\rho_{\mathrm{w}}$ denotes the charge density $\left(\mathrm{kg} / \mathrm{m}^{3}\right) ; D$ denotes the explosion velocity $(\mathrm{m} / \mathrm{s}) ; Q_{\mathrm{w}}$ denotes the explosive heat per unit mass $(\mathrm{J} / \mathrm{kg})$. The time history curve of blasting dynamic load shown in Figure 10 is generated, by setting the blasting parameters $\rho_{\mathrm{w}}=1630 \mathrm{~kg} / \mathrm{m}^{3}, D=6930$ $\mathrm{m} / \mathrm{s}, Q_{\mathrm{w}}=4.23 \mathrm{MJ} / \mathrm{kg}$ and the total charge $250 \mathrm{~kg}$.

In the static calculation of tunnel excavation, horizontal displacement constraint is applied to the surrounding boundary and vertical displacement constraint is applied to the bottom boundary. In tunnel blasting calculation, the model boundaries are changed to viscous boundaries to eliminate the false reflection.

3.2. Simulation of Rockburst Affected by Support Stiffness. We introduce the stress evolution, damage factor and strain energy index in order to elaborate the rock failure and rockburst effect under static and dynamic loads. Figure 11 compares the simulation of rockburst effects by using the accumulated strain energy and damage factor (the deterioration of the strength parameters in the strain-softening model). Under the weak stiffness support (Figure 11(a)), the failure area of surrounding rock mass is concentrated on the tunnel excavation face and located on the tunnel floor and right tunnel roof. The strain energy of the surrounding rock near the tunnel surface is markedly decreased; that is, the release zone of strain energy, where the regional damage factor increases to 1 (a full failure of the surrounding rock). The strain energy concentration is transferred to the deep surrounding rock. Under the strong stiffness support (Figure 11(b)), the failure and damage range of the surrounding rock is progressively expanding. The energy release zone near the tunnel excavation face penetrates the tunnel roof, right sidewall and tunnel floor; the maximum energy release reaches $0.25 \mathrm{MJ} / \mathrm{m}^{3}$.

In order to further reveal the fracture characteristics of rockburst disaster under the condition of strong and weak stiffness. The block velocity and fracture type of rockburst are simulated by discontinuous model (Figure 12). Under the condition of weak stiffness (Figure 12(a)), the rockburst occurs on the upper right and floor of the tunnel, and the maximum velocity of block ejection is $9.46 \mathrm{~m} / \mathrm{s}$. Under the condition of strong stiffness (Figure 12(b)), the failure strength and range of rockburst are obviously enhanced, and the maximum ejection velocity of the block is $13.9 \mathrm{~m} / \mathrm{s}$. In addition, in the fracture type diagram of rockburst block, the value 0 indicates no failure, the value 1 indicates tensile failure, and the value 2 indicates shear failure. It can be found that the main failure of rockburst is tension under the condition of weak stiffness, and the mixed failure type of tension and shear increases obviously under the condition of strong stiffness.

Figure 13 records the evolution of the maximum principal stress of the surrounding rock mass and lining. Under the weak stiffness support (Figure 13(a)), the maximum principal stress increases gradually during the five-step excavation and it declines after reaching the peak value. The lining stress drops behind the surrounding rock stress, which is affected by the damage and failure of rock mass. The surrounding rock further loses strength and has a secondary stress decline after the lining support fails. When the support stiffness is strengthened (Figure 13(b)), the maximum principal stress increases more severe than the weak-stiffness situation and reaches the peak value, followed by a rapid decline (representing the rockburst effect).

3.3. Mechanism Analysis. In order to interpret the rockburst effect under strong stiffness support, we categorize the stress evolution (Figure 13(b)) into three stages: the excavation stage A (static calculation), blasting vibration stage B (dynamic calculation) and rockburst stage $C$ (static and equilibrium calculation). The surrounding rock mass completes step-by-step excavation and strong lining support at the excavation stage. The lining stress is highly concentrated and far exceeds the surrounding rock stress, which indicates the 
TABLE 5: Mechanical parameters of rock mass and lining.

\begin{tabular}{lccccccc}
\hline $\begin{array}{l}\text { Mechanical } \\
\text { parameters }\end{array}$ & Density $\left(\mathrm{kg} / \mathrm{m}^{3}\right)$ & $\begin{array}{c}\text { Elastic } \\
\text { modulus }(\mathrm{Pa})\end{array}$ & $\begin{array}{c}\text { Poisson's } \\
\text { ratio }\end{array}$ & $\begin{array}{c}\text { Cohesive } \\
\text { strength }(\mathrm{Pa})\end{array}$ & $\begin{array}{c}\text { Tensile } \\
\text { strength }(\mathrm{Pa})\end{array}$ & $\begin{array}{c}\text { Friction } \\
\text { angle }\left(^{\circ}\right)\end{array}$ & $\begin{array}{c}\text { Shear expansion } \\
\text { angle }\left(^{\circ}\right)\end{array}$ \\
\hline $\begin{array}{l}\text { Rock mass (Tectonic } \\
\text { granulite) }\end{array}$ & 28.8 & $5.5 \times 10^{10}$ & 0.267 & $8 \times 10^{6}$ & $5 \times 10^{6}$ & 40.0 & 15 \\
$\begin{array}{l}\text { Weak-stiffness lining } \\
\begin{array}{l}\text { Strong-stiffness } \\
\text { lining }\end{array}\end{array}$ & 28 & $2.5 \times 10^{10}$ & 0.2 & $1.5 \times 10^{7}$ & $1.3 \times 10^{7}$ & 35.0 & 0 \\
\hline
\end{tabular}

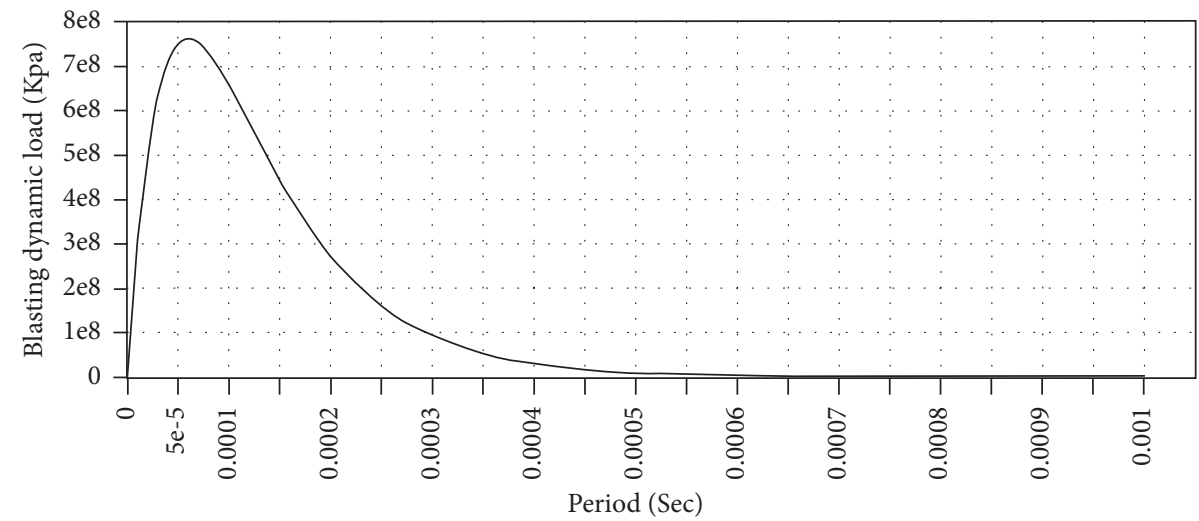

Figure 10: Time history curve of blasting dynamic load.

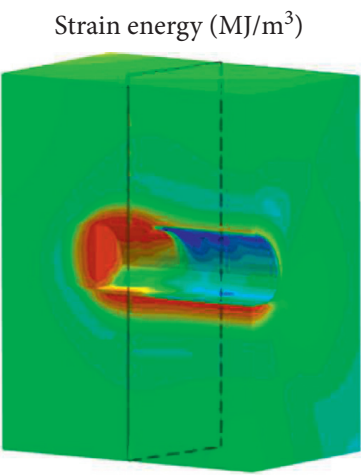

ป

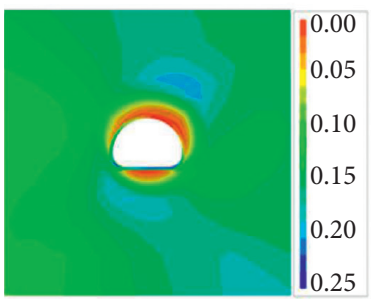

(a)

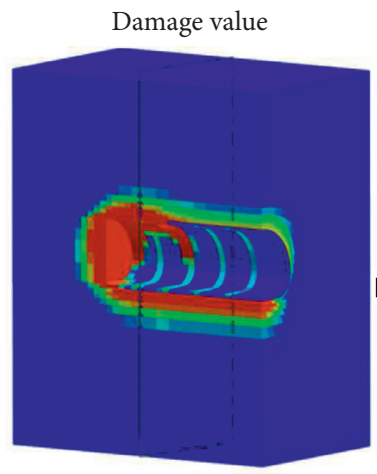

Љ

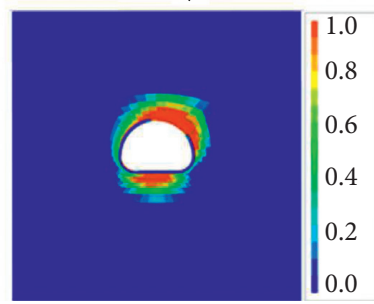

)

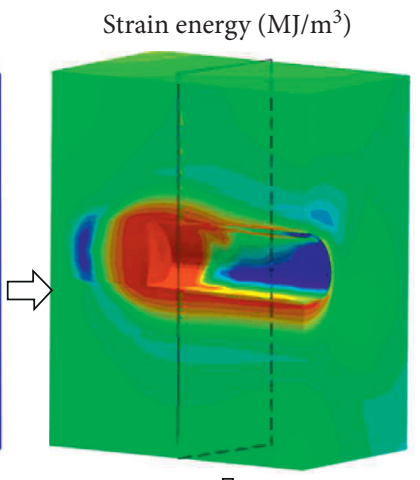

\)

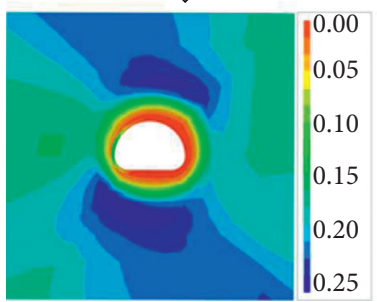

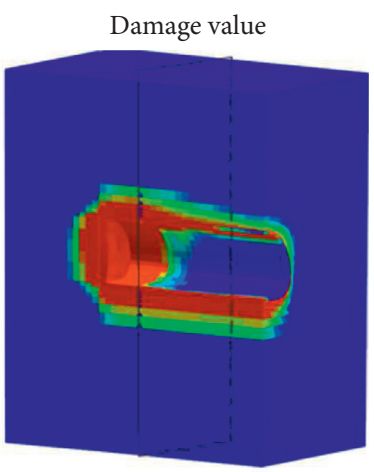

Љ

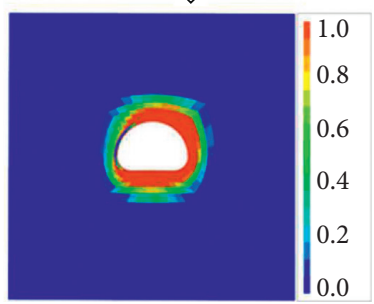

(b)

FiguRE 11: Simulation and comparison of rockburst effect (continuous model): (a) weak support stiffness; (b) strong support stiffness.

lining stress approaches the critical state of failure. In the blasting vibration stage, the lining has failed due to the stress fluctuation of blasting, and the lining stress decreases to a lower value. The failure of the lining causes the loss of support in the surrounding rock, which is similar to the sudden unloading effect in surrounding rock and results in the stress redistribution and rockburst stage.
Figure 14 presents the front stages (the excavation and blasting stages) of the strong-stiffness rockburst. The strong lining largely constrains the deformation of the surrounding rock at the excavation stage, and a large energy concentration occurs in the lining (the stress approaches the critical failure state); the damage value of the surrounding rock mass is not apparent. In the blasting vibration stage, the lining 
Rockburst block velocity (m/s)

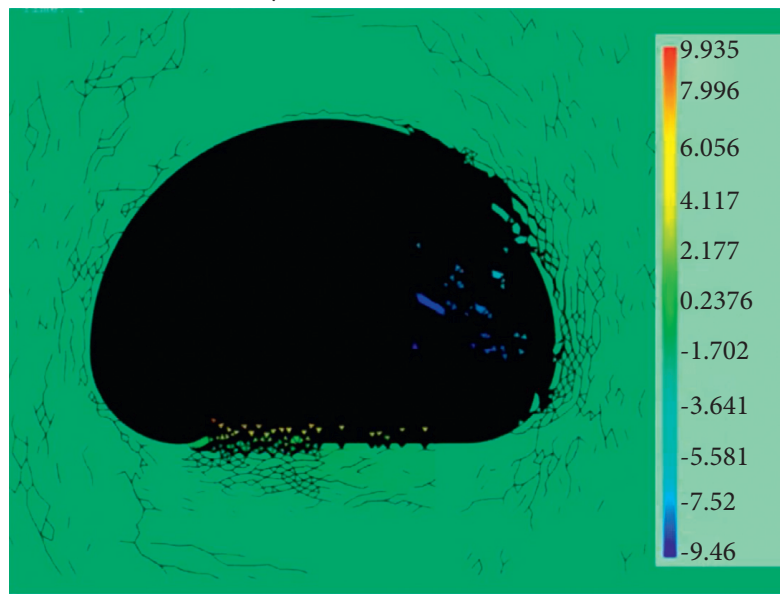

(a)

Rockburst block velocity (m/s)

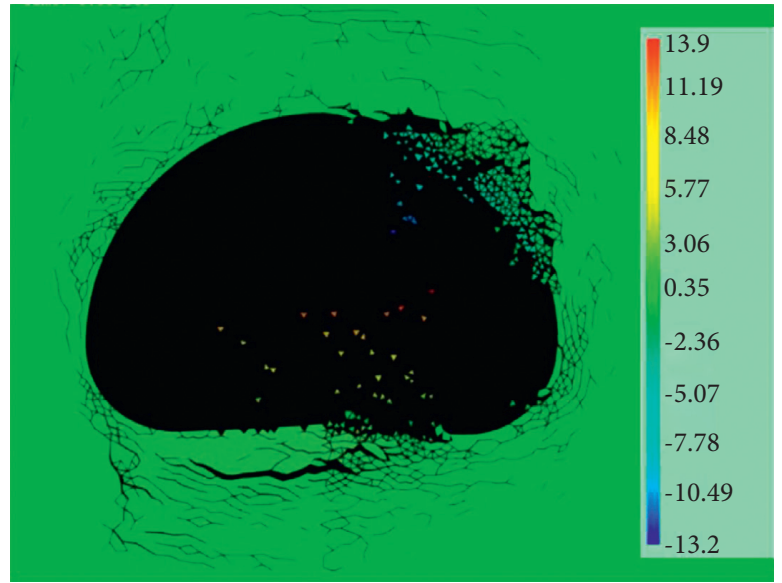

Fracture types of rockburst blocks

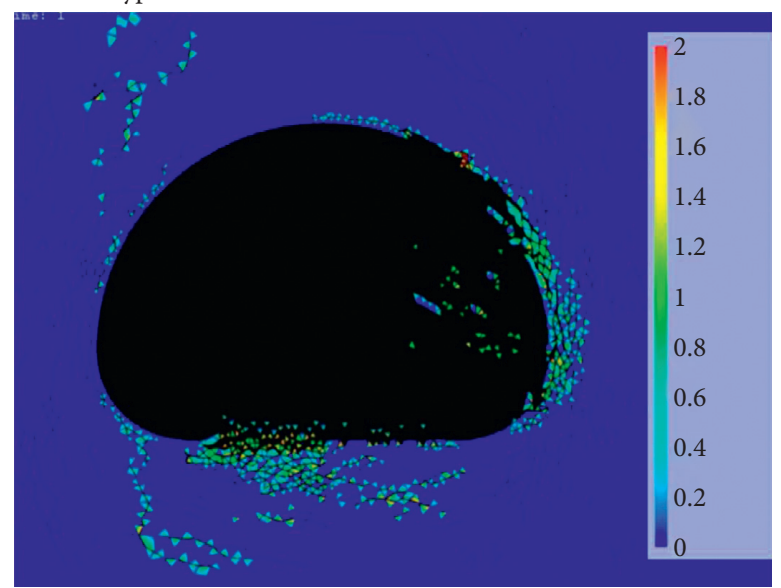

Fracture types of rockburst blocks

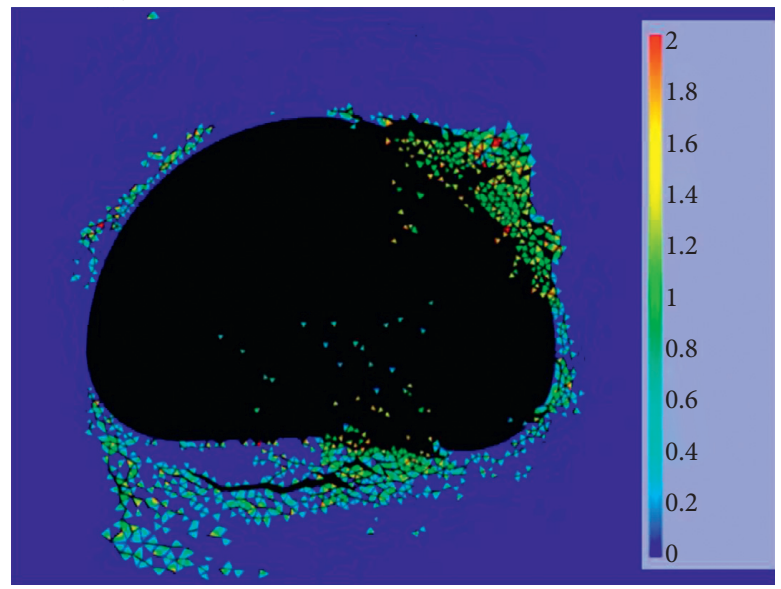

(b)

FIGURE 12: Simulation and comparison of rockburst disasters (discontinuous model): (a) weak support stiffness; (b) strong support stiffness.

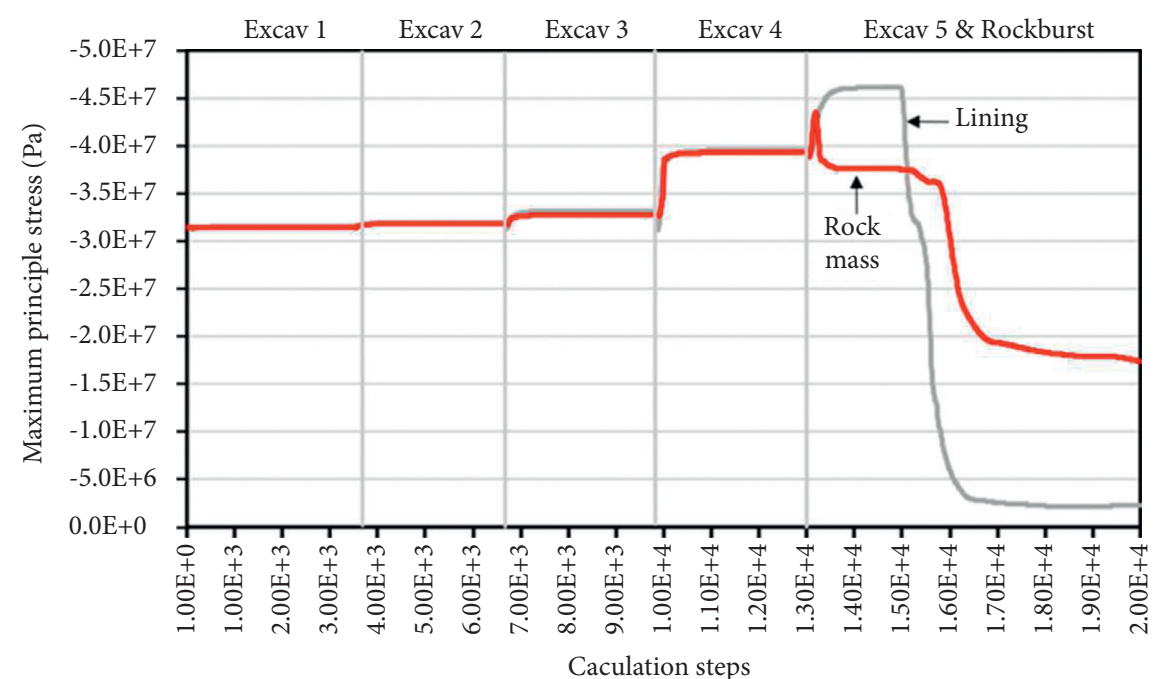

(a) 


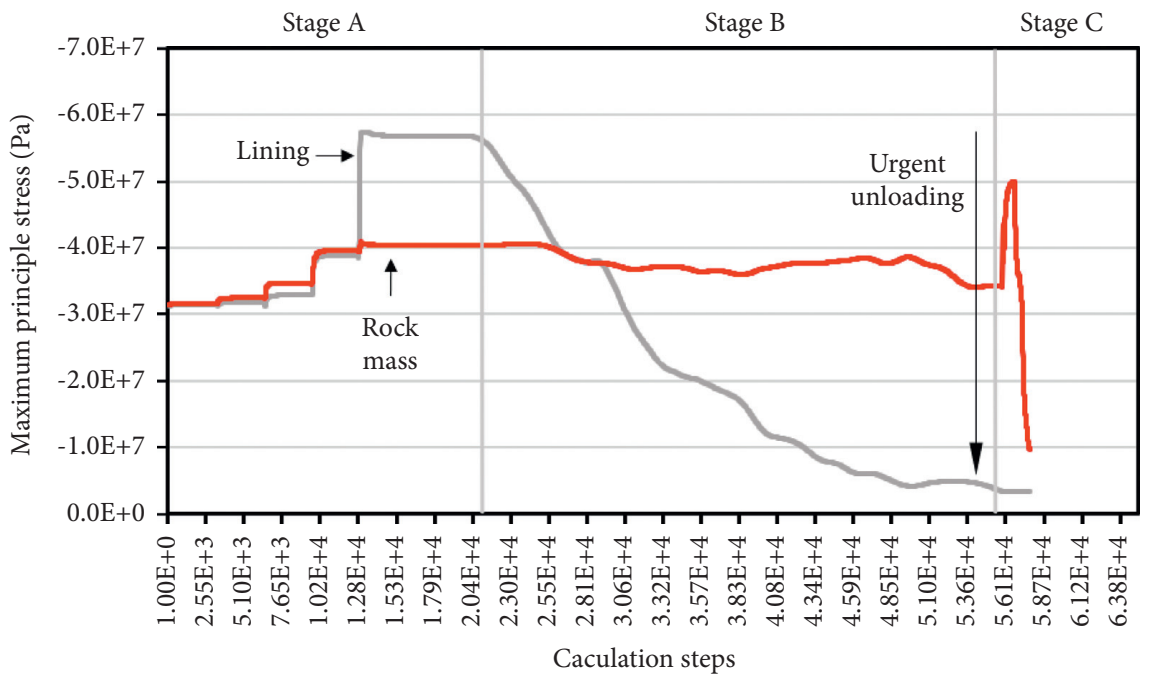

(b)

FIGURE 13: Stress monitoring of excavation and blasting during rockburst: (a) weak support stiffness; (b) strong support stiffness. Stage A is the excavation stage, stage $\mathrm{B}$ is the blasting vibration stage, and stage $\mathrm{C}$ is the rockburst stage.

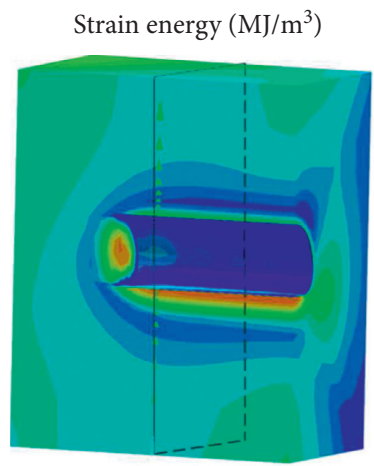

ก

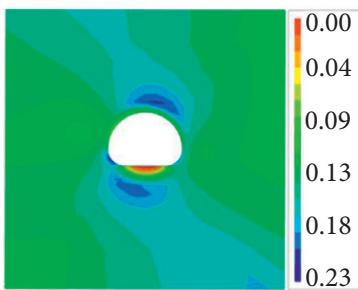

Damage value

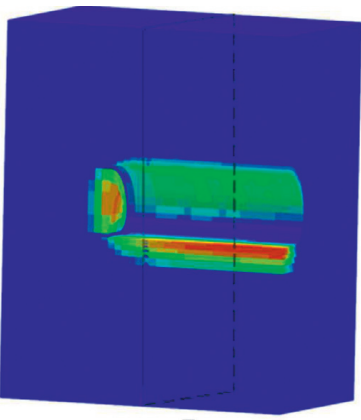

ת

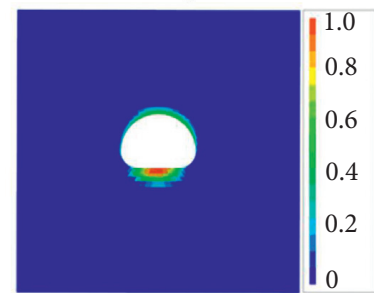

(a)

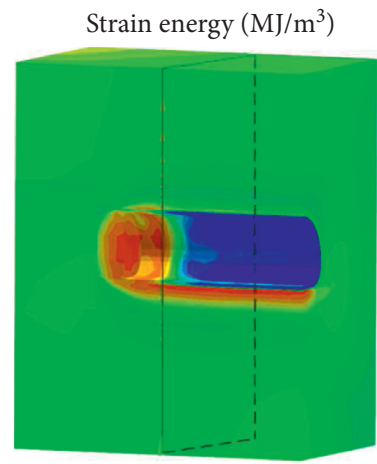

ת

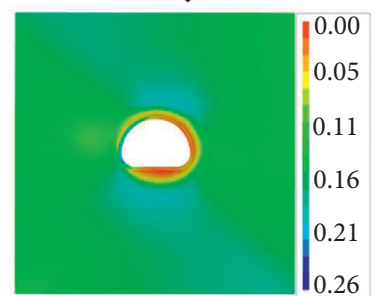

(b)

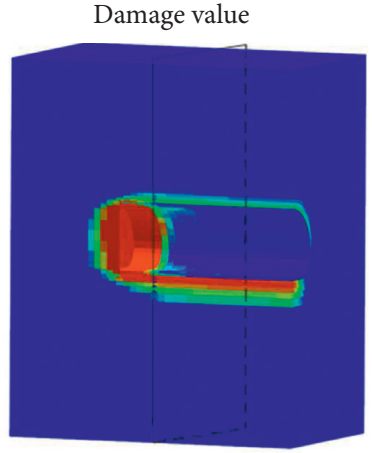

$\sqrt{3}$

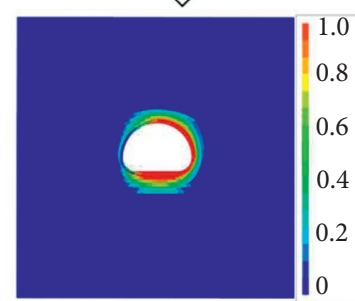

FIgURE 14: The simulation of front stages of rockburst under strong-stiffness support(continuous model): (a) the excavation stage; (b) the blasting vibration stage.

cracks before the surrounding rock mass, and the crack number of the lining far exceeds that of the surrounding rock (Figure 15); the energy concentration of the lining is released and its damage value reaches one, which would result in sudden unloading and rockburst effect of the surrounding rock mass.

Figure 16 presents the site damage and failure of tunnel lining. The lining often cracks even in the absence of 


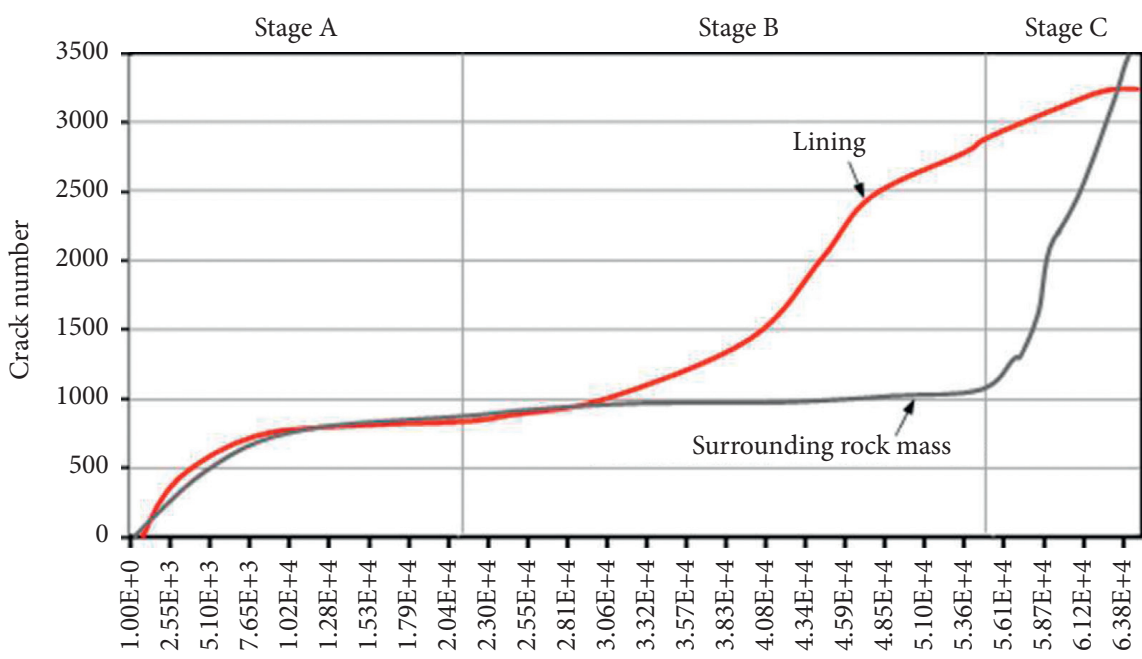

Caculation steps

FIGURE 15: The evolution of crack number during strong-stiffness rockburst
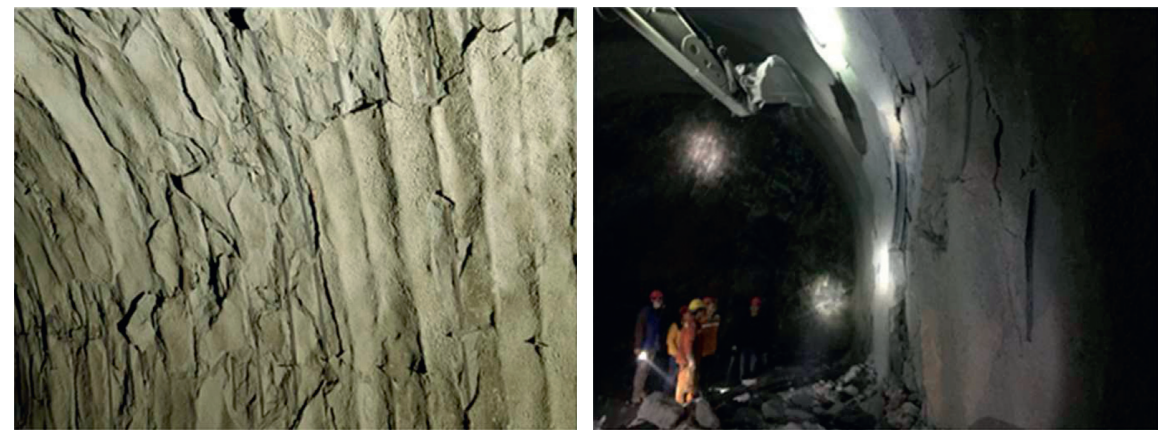

(a)
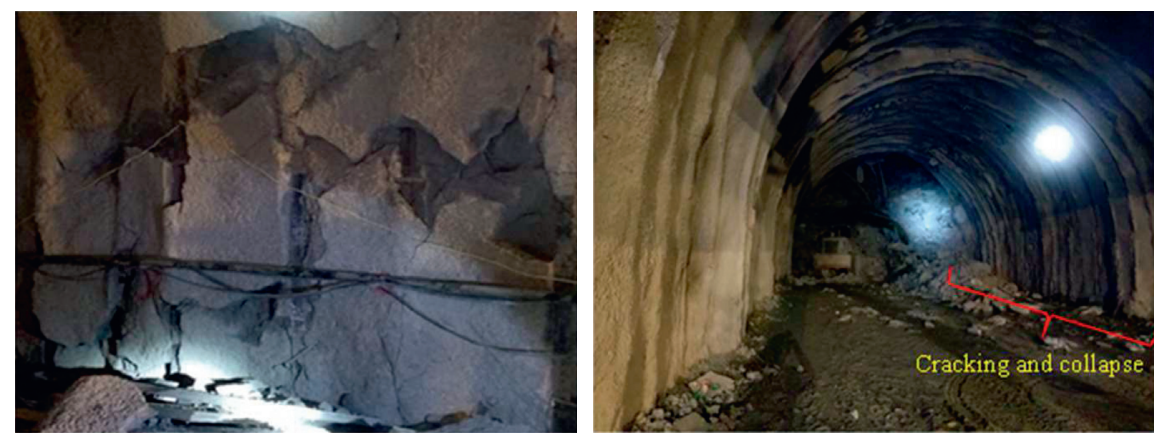

(b)

FiguRE 16: The lining crack before and after rockburst: (a) before the rockburst; and (b) after the rockburst.

rockburst due to the strong stiffness support applied to the high-stress surrounding rock (Figure 16(a)), which provides evidence for the existence of the sudden unloading effect. When rockburst occurs, large-scale cracks of the surrounding rock and lining crack could occur, and its range could reach $30 \mathrm{~m}$ (Figure 16(b)), including the lining crack in the front stage of rockburst and the lining crack caused by the strong energy release of rockburst. 


\section{Conclusions}

(1) The research shows that during the strong rock burst of Micangshan tunnel, the design of the initial support system greatly improves its strength and stiffness and poses a significant impact on the rockburst characteristics. The frequency of largeenergy microseismic event and the developmental period of rockburst increases. The rockburst is characterized by high intensity, strong energy release and wide affected range.

(2) Rockbursts with unique fracture and microseismic characteristics are selected to evaluate the impact of support stiffness from weak to strong. Strong stiffness support makes the surrounding rock unable to give full play to its self-supporting capacity in the excavation, thus accumulating higher energy. In the development of rockburst, the frequency of microseismicity largely increases; the intensity of microseismic events increases obviously; the cumulative microseismic source average displacement increases significantly (or suddenly). The characteristics of these indicators can be used as precursors to potential strong rockburst.

(3) Understanding the correlation between support system and microseismicity of surrounding rock mass is helpful to judge the suitability of support system. Strong stiffness support changes the microseismic event type, and the proportion of events with both low energy and large apparent volume increases, which indicates the development of rockburst tend to generate energy accumulation and energy transfer. At the same time, the microseismic activity of surrounding rock results in greater surrounding rock pressure, and the supporting structure is in a high stress concentration and near failure state. These phenomena indicate that the selection of support system should make the surrounding rock exert its self-supporting capacity and release the pressure of the surrounding rock.

(4) The rockburst effect is numerically simulated to illustrate the influence of strong stiffness support on rockburst. The stress of lining is highly concentrated after tunnel excavation and the lining is easily failed under the impact of external loads (such as tunnel blasting), which causes an "sudden unloading" effect on the surrounding rock mass and results in a stronger effect of rockburst. The site photo confirms the unloading effect of the lining on the surrounding rock.

(5) This study is helpful to clarify the mechanism of deep underground engineering support system on surrounding rock fracture, establish the early warning and support criterion of deep engineering rockburst, which can ensure the safe and efficient engineering activities. However, our findings could be subject to the particularity of engineering and geological conditions. It is necessary to further explore the mechanical effects of support system on rockburst and reveal the interaction between support system and microseismicity.

\section{Data Availability}

The underlying data supporting the results of our study are unavailable.

\section{Conflicts of Interest}

No potential conflict of interest was reported by the authors.

\section{Acknowledgments}

The authors acknowledge the financial support from the Cooperative Project of National Defense Engineering Research Institute of Academy of Military Sciences (contract No. 2019-JKGF-C01-1003); National Natural Science Foundation of China (grant No. 41807255).

\section{References}

[1] G.-L. Feng, X.-T. Feng, B.-R. Chen, Y.-X. Xiao, and Y. Yu, “A microseismic method for dynamic warning of rockburst development processes in tunnels," Rock Mechanics And Rock Engineering, vol. 48, no. 5, pp. 2061-2076, 2015.

[2] T. Li, C. Ma, M. Zhu, L. Meng, and G. Chen, "Geomechanical types and mechanical analyses of rockbursts," Engineering Geology, vol. 222, pp. 72-83, 2017.

[3] H.-P. Xie, F. Gao, Y. Ju, R. Zhang, M.-Z. Gao, and J.-H. Deng, "Novel idea and disruptive technologies for the exploration and research of deep earth," Engineering science and technology, vol. 49, no. 1, pp. 1-8, 2017.

[4] Y. Yu, X.-T. Feng, C.-J. Xu, B.-R. Chen, Y.-X. Xiao, and G.-L. Feng, "Spatial fractal structure of microseismic events for different types of rockburst in deeply buried tunnels," International Journal of Geomechanics, vol. 20, no. 4, 2020.

[5] M.-W. Wang, Q.-Y. Liu, X. Wang, F.-Q. Shen, and J.-L. Jin, "Prediction of rockburst based on multidimensional connection cloud model and set pair analysis," International Journal of Geomechanics, vol. 20, no. 1, 2020.

[6] A. Keneti and B.-A. Sainsbury, "Review of published rockburst events and their contributing factors," Engineering Geology, vol. 246, pp. 361-373, 2018.

[7] F. Meng, H. Zhou, Z. Wang et al., "Experimental study of factors affecting fault slip rockbursts in deeply buried hard rock tunnels," Bulletin of Engineering Geology and the Environment, vol. 76, no. 3, pp. 1167-1182, 2017.

[8] C.-C. Ma, T.-B. Li, and H.-L. Xing, "Microseismic and precursor analysis of high-stress hazards in tunnels: a case comparison of rockburst and fall of ground," Engineering Geology, vol. 265, pp. 105-435, 2020.

[9] B.-A. Sainsbury and N. Kurucuk, "Impact of intact rock properties on proneness to rockbursting," Bulletin of Engineering Geology and the Environment, vol. 79, no. 4, pp. 1939-1946, 2020.

[10] N. W. Xu, T. B. Li, F. Dai, R. Zhang, C. A. Tang, and L. X. Tang, "Microseismic monitoring of strainburst activities in deep tunnels at the jinping II hydropower station, China," Rock Mechanics and Rock Engineering, vol. 49, no. 3, pp. 981-1000, 2016. 
[11] H. Zhou, F. Meng, C. Zhang, D. Hu, F. Yang, and J. Lu, "Analysis of rockburst mechanisms induced by structural planes in deep tunnels," Bulletin of Engineering Geology and the Environment, vol. 74, no. 4, pp. 1435-1451, 2015.

[12] Y. Fan, W.-B. Lu, Y.-H. Zhou, P.-Z. Yan, D. Leng, and M. Chen, "Influence of tunneling methods on the strainburst characteristics during the excavation of deep rock masses," Engineering Geology, vol. 201, pp. 85-95, 2015.

[13] G.-Y. Hu, "Influence of support thickness on rockburst strength," Inner Mongolia Science and Technology and Economics, vol. 9, pp. 54-56, 2018.

[14] J. Li, L.-Q. Liu, G.-W. Miu, H.-X. He, and M.-H. Li, "Research and application of deep mining roadway support technology in Chener Gold Mine," Gold, vol. 39, no. 4, pp. 31-35, 2018.

[15] K. Chen, "Study of strainburst process under rockbolt support condition," Master's Thesis, Guangxi University, Nanning, China, 2017.

[16] W. D. Ortlepp, "High ground displacement velocities associated with rockburst damage," in Proceedings of the Third International Symposium on Rockbursts and Seismicity in Mines, Kingston, Ontario, 1993.

[17] W.-D. Ortlepp, Rock Fracture and Rockbursts: An Illustrative Study, The South African Institute of Mining and Metallurgy, Johannesburg, South Africa, 1997.

[18] G.-T. Huang, "Research on the prediction and prevention of rockburst of Cuihuashan super long tunnel in Qinling Mountain," Master's Thesis, Xi'an University of Architectural Science and Technology, Xi'an, China, 2013.

[19] J. M. Alcott, P. K. Kaiser, and B. P. Simser, "Use of microseismic source parameters for rockburst hazard assessment," Pure and Applied Geophysics, vol. 153, no. 1, pp. 41-65, 1998.

[20] G. K. Ghosh and C. Sivakumar, "Application of underground microseismic monitoring for ground failure and secure longwall coal mining operation: a case study in an Indian mine," Journal of Applied Geophysics, vol. 150, pp. 21-39, 2018.

[21] C. Ma, Y. Jiang, and T. Li, "Gravitational search algorithm for microseismic source location in tunneling: performance analysis and engineering case study," Rock Mechanics and Rock Engineering, vol. 52, no. 10, pp. 3999-4016, 2019.

[22] P.-M. Shearer, Introduction to Seismology, Cambridge: Cambridge University Press, Cambridge, UK, 2009.

[23] H. Zhang, C.-C. Ma, and T.-B. Li, "Quantitative evaluation of the "Non-Enclosed" microseismic array: a case study in a deeply buried twin-tube tunnel," Enerigies, vol. 12, no. 10, 2019.

[24] D. Zhuang, K. Ma, C. Tang, Z. Liang, Z. Wang, and F.-Q. Gong, "Microseismic monitoring of energy changes in deep tunnels during the TBM tunneling of the jinping II hydropower station," Advances in Civil Engineering, vol. 2018, Article ID 5364628, 15 pages, 2018.

[25] Y. Zhao, T. Yang, M. Bohnhoff et al., "Study of the rock mass failure process and mechanisms during the transformation from open-pit to underground mining based on microseismic monitoring," Rock Mechanics and Rock Engineering, vol. 51, no. 5, pp. 1473-1493, 2018.

[26] L. Hu, X.-T. Feng, Y.-X. Xiao et al., "Characteristics of the microseismicity resulting from the construction of a deeplyburied shaft," Tunnelling and Underground Space Technology, vol. 85, pp. 114-127, 2019.

[27] W.-J. Gale, K.-A. Heasley, and A.-T. Iannacchione, "Rock damage characterisation from microseismic monitoring," in Proceedings of the 38th U.S. Rock Mechanics Symposium, Washington, DC, USA, July 2001.
[28] C.-C. Ma, T.-B. Li, H. Zhang, Y.-X. Han, and X.-H. Zhou, “A preliminary study on the effect of the support system stiffness on the microseismic characteristics of rockburst," Journal of rock mechanics and engineering, vol. 38, pp. 2976-2987, 2019.

[29] C.-L. Li, "Rockburst conditions and rockburst support," Journal of rock mechanics and engineering, vol. 38, no. 4, pp. 1-9, 2019.

[30] T. C. Hanks and H. Kanamori, "A moment magnitude scale," Journal of Geophysical Research, vol. 84, no. B5, pp. 23482350, 1979.

[31] F. Dai, B. Li, N. Xu, and Y. Zhu, "Microseismic early warning of surrounding rock mass deformation in the underground powerhouse of the Houziyan hydropower station, China," Tunnelling and Underground Space Technology, vol. 62, pp. 64-74, 2017.

[32] H. Zhang, J. Zeng, J.-J. Ma et al., "Time series prediction of microseismic multi-parameter related to rockburst based on deep learning," Rock Mechanics and Rock Engineering, vol. 54, no. 12, pp. 1-23, 2021. 